\title{
Outcome of Mode of Delivery in Nulliparous and Multiparous Women Presenting with Early and Late Cervical Dilatation
}

\author{
Ferdous Ara Shuchi ${ }^{1}$, Salma Lovereen ${ }^{2}$, Mst. Nazumnnaher Mina ${ }^{3}$
}

\begin{abstract}
Background: Knowledge of the patterns of normal and abnormal labour, and of women's behavior, is fundamental to the formulation of mode of delivery. It is observed that women admitted to hospital early have a higher frequency of obstetric interventions in labour than those admitted later. Objective: To study the outcome of spontaneous onset of labour in nulliparous and multiparous patients. Materials and method: During the study period of 1st July 2008 to 31st Dec 2008, 568 pregnant women admitted in Kumudini Women's Medical College were included in this study. Mothers were observed since admission with spontaneous onset of labour and followed up till they were released from the hospital. Labour outcome was measured and mode of delivery was compared among nulliparous and multiparous women. Results: Among the nulliparous women, normal vaginal delivery occurred in 71 (23\%) patients presented with early cervical dilatation $(0-3 \mathrm{~cm})$ and in $142(46 \%)$ patients presented with late cervical dilatation (>4 cm). In nulliparous women caesarean section were needed in 60 (45.8\%) patients in early cervical dilatation group and in 35 (19.8\%) patients in late cervical dilatation group. In multiparous women, normal vaginal delivery occurred in 66 (25\%) patients presented with early cervical dilatation and in 133 (51\%) patients presented with late cervical dilatation whereas cesarean section were done in 35 (34.7\%) patients and in $25(15.8 \%)$ patients in the two groups respectively. Duration of labour between nulliparous and multiparous was significantly different ( 8 hours vs. 6 hours). Indication of caesarean section were, 61 (40\%) patients due to prolong labour, 48 (34\%) due to foetal distress and $44(26 \%)$ due to cephalopelvic disproportion. Conclusion: Normal vaginal delivery occurred more and duration of labour was shorter in patients admitted with advanced labour (cervical dilatation $>4 \mathrm{~cm}$ ).
\end{abstract}

Keywords: onset of labour; duration of labour; mode of delivery.

$$
\text { Delta Med Col J. Jan 2019;7(1):16-20 }
$$

\section{Introduction}

Rates of caesarean section have been a major public health concern in Bangladesh in recent years. Most caesarean sections for nulliparous women are performed for dystocia, and this is exceeded only by previous caesarean section as an indication for caesarean delivery. However, the study of antenatal and intrapartum predictors of caesarean section in labour has not yet produced a model with high sensitivity and specificity. 1,2 Knowledge of the patterns of normal and abnormal labour, and of women's behavior, is fundamental to the formulation of strategies to

1. Professor \& Head, Dept. of Obstetrics \& Gynaecology, Delta Medical College, Dhaka, Bangladesh.

2. Associate professor, Dept. of Obstetrics \& Gynaecology, Ibn Sina Medical College, Dhaka, Bangladesh.

3. Assistant professor, Dept. of Obstetrics \& Gynaecology, Delta Medical College, Dhaka, Bangladesh.

Correspondence: Dr. Ferdous Ara Shuchi. e-mail: suchi1162@yahoo.com 
reduce caesarean section rates. One of the difficult decisions that women have to make during a pregnancy is the decision when to go into hospital if they think that labour may be beginning. Nulliparous women in particular have no experience of labour and so may find the timing of presentation to hospital particularly difficult to judge. In addition, in many western countries there is increasing centralization of health resources, which may lead to increased journey times to the hospital. But in Bangladesh this system is far apart. A previous study has shown that women admitted to hospital early (contractions of four hours or less) have a higher frequency of obstetric interventions in labour than those admitted later. ${ }^{3}$

The objective of this study was to determine how the caesarean section rate changes with the cervical dilatation at which women present in labour. Other outcome measures were operative and spontaneous vaginal delivery, duration of labour, labour augmentation with oxytocin. In addition the effect of deferring admission, in women presenting in early labour, was examined.

\section{Materials and method}

This is a retrospective study for cases admitted in Kumudini Women's Medical College during the period of July 2006 to December 2006. Total admission in obstetric word was 1492. Among them 265 patients were admitted due to pregnancy with non-obstetric complains and were treated conservatively. Total number of deliveries were 1227. Normal vaginal deliveries were 671 and caesarean section were 556. Among total deliveries 568 patients fulfilled the inclusion criteria.

Incusion criteria were - nulliparous or multiparous women in spontaneous labour with a singleton pregnancy, cephalic presentation, gestational age 37-42 wks, adequate pelvis whose delivery occured within $36 \mathrm{hrs}$ of admission. Women were categorized as having early if they attended at 0-3 $\mathrm{cm}$ cervical dilatation or late if they presented with a cervical dilatation of $>4 \mathrm{~cm}$.
Exclusion criteria were - preterm labour, postmature pregnancy, premature rupture of membrane (PROM), malpresentation, eclampsia, antepartum haemorrhage, intrauterine death, history of previous caesarean section and multiple pregnancy.

The outcome of labour was noted with regard to caesarean section and spontaneous vaginal delivery, foetal weight, and five minute APGAR score. Frequencies of labour augmentation with oxytocin was also noted. The patient was examined at the time of admission and patients who are in labour was included in the study group. Duration of labour was calculated from the admission of the mother to the delivery of the baby.

\section{Result}

Of 1227 deliveries during the study period, 568 were singleton cephalic deliveries at 37-42 weeks. Out of them 415 had NVD, and 99 women out of this were augmented with oxytocin, 316 women delivered without oxytocin and 153 needed delivery by caesarean section. Among the 568 women forming the study population, 309 were nulliparous and 259 were parous.

Demographic data are shown in Table I. Most mothers were between 21-30 years. Only 2 of them were of more than 40 years.

Table I: Distribution of the study subjects by age $(\mathrm{N}=568)$

\begin{tabular}{|c|c|c|c|c|c|c|c|c|}
\hline \multirow[t]{3}{*}{ Age (years) } & \multicolumn{4}{|c|}{ Nulliparous ( $\mathrm{n}=309$ ) } & \multicolumn{4}{|c|}{ Parous $(n=259)$} \\
\hline & \multicolumn{2}{|c|}{$\begin{array}{l}0-3 \mathrm{~cm} \\
(\mathrm{n}=132)\end{array}$} & \multicolumn{2}{|c|}{$\begin{array}{l}4-10 \mathrm{~cm} \\
(n=177)\end{array}$} & \multicolumn{2}{|c|}{$\begin{array}{c}0-3 \mathrm{~cm} \\
(\mathrm{n}=101)\end{array}$} & \multicolumn{2}{|c|}{$\begin{array}{l}4-10 \mathrm{~cm} \\
(n=158)\end{array}$} \\
\hline & $\mathrm{n}$ & $\%$ & $\mathrm{n}$ & $\%$ & $\mathrm{n}$ & $\%$ & $\mathrm{n}$ & $\%$ \\
\hline$<\mathbf{2 0}$ & 48 & 36.4 & 69 & 39 & 9 & 8.9 & 16 & 10.1 \\
\hline 21-30 & 83 & 62.9 & 106 & 59.9 & 81 & 80.2 & 117 & 74.1 \\
\hline $31-40$ & 1 & 0.8 & 2 & 1.1 & 9 & 8.9 & 25 & 15.8 \\
\hline$>40$ & 0 & 0 & 0 & 0 & 2 & 2 & 0 & 0 \\
\hline
\end{tabular}

Duration of labour in nulliparous and multiparous women are shown in table II. Duration of labour between nulliparous and multiparous was significantly different. Nulliparous patients had longer duration of labour with mean time of 8 hours than multiparous who had mean time of 6 
hours. Women who presented to hospital at 0-3 cm spent more time in labour than those presenting in advanced labour.

Table II: Distribution of the study subjects by duration of labour $(\mathrm{N}=568)$

\begin{tabular}{|c|c|c|c|c|c|c|c|c|}
\hline \multirow{3}{*}{$\begin{array}{l}\text { Duration of } \\
\text { labour (hours) }\end{array}$} & \multicolumn{4}{|c|}{ Nulliparous $(n=309)$} & \multicolumn{4}{|c|}{ Parous $(n=259)$} \\
\hline & \multicolumn{2}{|c|}{$\begin{array}{l}0-3 \mathrm{~cm} \\
(\mathrm{n}=132)\end{array}$} & \multicolumn{2}{|c|}{$\begin{array}{l}4-10 \mathrm{~cm} \\
(n=177)\end{array}$} & \multicolumn{2}{|c|}{$\begin{array}{l}0-3 \mathrm{~cm} \\
(\mathrm{n}=101)\end{array}$} & \multicolumn{2}{|c|}{$\begin{array}{l}4-10 \mathrm{~cm} \\
(\mathrm{n}=158)\end{array}$} \\
\hline & $\mathrm{n}$ & $\%$ & $\mathrm{n}$ & $\%$ & $\mathrm{n}$ & $\%$ & $\mathrm{n}$ & $\%$ \\
\hline$<5$ hrs & 35 & 26.5 & 152 & 85.9 & 20 & 19.9 & 131 & 82.9 \\
\hline 6-10 hrs & 55 & 41.6 & 12 & 6.8 & 48 & 47.5 & 12 & 7.6 \\
\hline 11-15 hrs & 17 & 12.9 & 11 & 6.2 & 12 & 11.9 & 11 & 6.9 \\
\hline$>15 \mathrm{hrs}$ & 25 & 18.9 & 2 & 1.1 & 21 & 20.8 & 4 & 2.5 \\
\hline
\end{tabular}

In Fig 1 rates of normal vaginal delivery and caesarean section among nulliparous and parous mothers presenting with early and late cervical dilatation are compared. The rate of caesarean section was less with increasing cervical dilatation on presentation for both nulliparous and multiparous women. In nulliparous women, normal vaginal delivery occurred in $72(23 \%)$ patients presented with early cervical dilatation and in $142(46 \%)$ patients presented with late cervical dilatation. In this group caesarean section were needed in $60(45.8 \%)$ patients with early cervical dilatation and in $35(19.8 \%)$ patients with late cervical dilatation.

In parous women, normal vaginal delivery occurred in $66(25 \%)$ patients presented with early cervical dilatation whereas in $133(51 \%)$ patients presented with late cervical dilatation. In these parous patients, caesarean section were needed in $35(34.7 \%)$ patients with early cervical dilatation and in $25(15.8 \%)$ patients with late cervical dilatation.

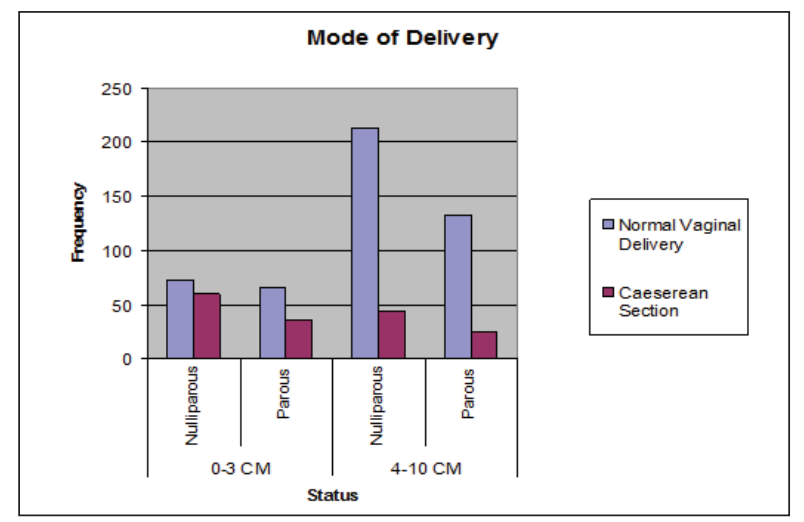

Fig 1: Distribution of the study subjects by mode of delivery $(\mathrm{N}=568)$
Overall causes of caesarean section are shown in Fig 2 which shows the leading cause of caesarean section was prolonged labour due to dystocia $(40 \%)$.

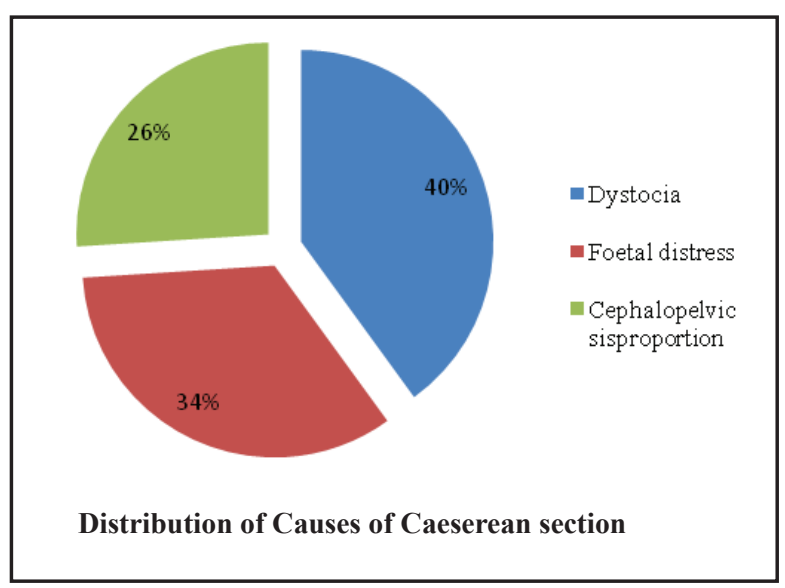

Fig 2: Causes of caesarean section

Deliveries with oxytocin augmentation are shown in Fig 3. Out of 568 pregnant women, 415 (73\%) had NVD, of these $99(24 \%)$ were induced with oxytocin. Total 153 (59\%) mothers delivered by caesarean section, of these in $13(8 \%)$ mothers labour was induced with oxytocin (Fig 3).

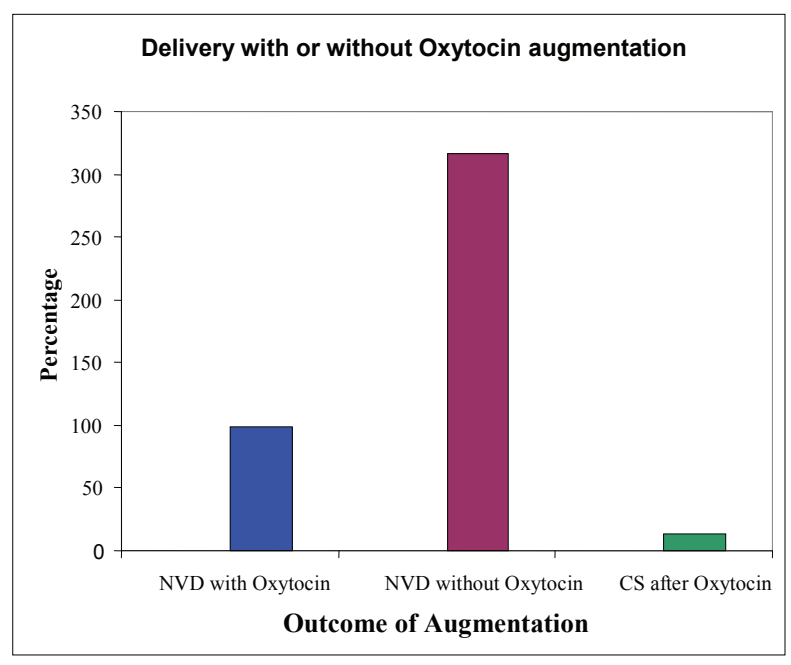

Fig 3: Delivery with or without oxytocin

\section{Discussion}

This study shows that in both primiparous and multiparous patients who present with early cervical dilatation on admission have more chance of caesarean section than NVD. But duration of 
labour between nulliparous and multiparous patients are different. Nulliparous patients had longer duration of labour than multiparous. In this study we found that common cause of caesarean section was prolonged labour due to dystocia, which is defined as abnormal or difficult labour.

Hemminki et al. observed those women who admitted to the hospital in early phase had more intervention during labour, more caesarean sections, and longer postpartum hospital stay in comparison to those coming late in active phase. ${ }^{3}$ This is also approved in our study.

Deidre et al. found that among women who delivered by caesarean, lack of progress was commonly diagnosed in the latent phase of labour. They found that in $51 \%$ of the caesareans were done for lack of progress of labour. Other indications for the caesarean were also recorded. The most common of these was non reassuring fetal status, which was present in $21 \%$ of caesareans, and their findings are similar to our findings. ${ }^{4}$

Paule et al. also demonstrated that women who present to hospital early in labour have higher risk of caesarean section and oxytocin induction than those who present later. ${ }^{5}$ Those presenting early may have dysfunctional latent phase of labour, they might have laboured for a long time attending hospital than women who presented later. $^{5}$ Chelmow et al. found prolonged latent phase has been shown to be independently associated with an increased incidence of caesarean section and other labour abnormality. ${ }^{6}$ This is also in line with our study.

Debra et al. showed later admission in labour at 4 $\mathrm{cm}$ or greater cervical dilatation had increased rate of spontaneous vaginal delivery in low risk women. ${ }^{7}$ This result is comparable to our study. Stewart et al. found that $40 \%$ of caesarean section was done for dystocia diagnosed during latent phase, ${ }^{8}$ which is similar to our study. Rate of augmentation in both groups was nearly similar. Impely et al. showed augmentation of labour that has begun spontaneously, reduces the duration of first stage of labour ${ }^{9}$ which is comparable with our study.
It is well recognized that high level of pain and anxiety are associated with increased intervention in labour, and that the provision of support, in hospital, for women in childbirth reduces both anxiety and obstetric intervention. ${ }^{10-13}$ Early admission to hospital may itself have had an effect on labour through differences in maternal position or ambulation. ${ }^{14}$ Although this issue was not specifically addressed in our study. One major distinction between the early and late presenters is the absence of date relating to the duration of the latent phase of labour in the late presenters. Intervention rates may be higher when physicians are provided with this information. ${ }^{15}$

The lack of a beneficial effect of deferred admission suggests that the increased intervention associated with early attendance is a result of intrinsic maternal or obstetric characteristics, and may not be due to unnecessary medical intervention. Indeed, it could be argued that this group of women are at higher risk of caesarean section and other interventions, and may benefit from early admission and close monitoring.

However, there is also some evidence that home assessment in early labour can delay hospital attendance with a concomitant reduction in intervention. ${ }^{16}$ We feel the factors which cause women to seek early admission are an important area for further study.

In the light of our observation, NVD occurred more and duration of labour is short in patients admitted with advanced labour (cervical dilatation $>4 \mathrm{~cm}$ ). Caesarean section were needed more and duration of labour is more in patients admitted with early labour.

\section{References}

1. Hin LY, Lau TK, Rogers M, Chang AM. Antepartum and Intrapartum Prediction of Caesarean Need: Risk Scoring in Singleton Pregnancies. Obstet Gynecol. 1997;90:183-86.

2. The Canadian Early Amniotomy Study Group; Turcot L, Marcoux S, Fraser WD. Multivariate Analysis of Risk Factors for Operative Delivery in Nulliparous Women. Am J Obstet Gynecol. 1997;176:395-402. 
3. Hemminki E, Simukka R. The Timing of Hospital Admission and Progress of Labour. Eur J Obstet Gynecol Reprod Biol. 1986;22:85-94.

4. Gifford DS, Morton S, Fiske M. Lack of Progress in Labour as Reason for Caesarean. Obstetrics \& Gynaecology. 2000;95:589-95.

5. Homes P, Lawrence W. The Relationship between Cervical Dilatation at Initial Presentation in Labour \& Subsequent Intervention. Br J Obstet Gynecol. 2001;108(11):1120-24.

6. Chelmow D, Kilpatric SJ, Laros RK. Maternal \& Neonatal Outcomes after Prolonged Latent Phase. Obstetrics \& Gynaecology. 1993;81:486-91.

7. Jackson DJ, Janet M, Lang JM. Impact of Collaborative Management and Early Admission in Labour on Method of Delivery. Journal of Obstetrics, Gynaecology, and Neonatal Nursing. 2003;23:147.

8. Stewart P, Dulberg J. Diagnosis of Dystocia \& Management with Caesarean Section among Primiparous Women in Ottawa-Carteton. Canadian Medical Association Journal. 1990;142(5):459-63.

9. Impey L, Hobson J. Graphic Analysis of Actively Managed Labour. American J of Obstetric Gynecol. 2000;183(2):438-43.

10. Wuitchik M, Bakal D, Lipshitz J. The Clinical Significance of Pain and Cognitive Activity in Latent Labour. Obstet Gynecol. 1998;73:35-42.
11. Ryding EL, Wijma B, Wijma K, Rydhstrom H. Fear of Childbirth During Pregnancy May Increase the Risk of Caesarean Section. Acta Obstet Gynecol Scand. 1998;77:542-47.

12. Zhang J, Bernasko JW, Leybovich E, Fahs M, Hatch Mc. Continuous Labour Support from Labour Attendant for Primiparous Women: A Meta-Analysis. Obstet Gynecol. 1996;88:739-44.

13. Hodnett ED. Caregiver Support for Women During Childbirth. Cochrane Database System Review. 2000;2:CD000199.

14. Flynn AM, Kelly J, Hollins G, Lynch PF. Ambulation in Labour. BMJ. 1978;2:591-93.

15. Cartmill RSV, Thornton JG. The Effect of Partogram Information on Obstetric Decision Making. Lancet. 1992;339:1520-22.

16. Klein M, Lloyd I, Redman C, Bull M, Turnbull AC. A Comparison of Low Risk Pregnant Women Booked for Delivery in Two Systems of Care: Shared-Care (Consultant) and Integrated General Practice Unit II. Labour and Delivery Management and Neonatal Outcome. Br J Obstet Gynecol. 1983;90:123-28. 